\title{
Early Reduction of Total $N$-Acetyl-Aspartate-Compounds in Patients With Classical Vanishing White Matter Disease. A Long-Term Follow-Up MRS Study
}

\author{
STEFFI F. DREHA-KULACZEWSKI, PETER DECHENT, JÜRGEN FINSTERBUSCH, KNUT BROCKMANN, JUTTA GÄRTNER,
} JENS FRAHM, AND FOLKER A. HANEFELD

\begin{abstract}
Department of Pediatrics and Pediatric Neurology [S.F.D.-K., K.B., J.G., F.A.H.], MR-Research in Neurology and Psychiatry [P.D.], Georg August University, 37075 Göttingen, Germany; Department of System Neuroscience [J. Finsterbusch], University Medical Center Hamburg-Eppendorf, 20246 Hamburg, Germany; Biomedizinische NMR Forschungs GmbH am Max-Planck-Institut für biophysikalische Chemie [J. Frahm], 37070 Göttingen, Germany
\end{abstract}

\begin{abstract}
The neuropathology of vanishing white matter (VWM) disease is characterized by a loss of white matter (WM). Although recent histopathological studies suggest a primary glial dysfunction, the purpose of this work was to assess the extent of axonal involvement in VWM using long-term follow-up proton MR spectroscopy. White and gray matter of nine children with genetically proven VWM and late infancy/early childhood onset were investigated with short-echo time, single-voxel proton MR spectroscopy over up to 8 years starting as early as less than 2 years after the onset of symptoms (5 patients). Total $N$-acetyl-aspartate $(-51 \%$ from normal control), creatine and phosphocreatine $(-47 \%)$, and myo-inositol $(-49 \%)$ were reduced in WM at early disease stages. Cholinecontaining compounds were less severely decreased ( $-31 \%)$. Follow-up investigations revealed progressive reduction of all metabolites in WM. In gray matter, no distinct changes were detected at early stages. Later total $\mathrm{N}$-acetyl-aspartate decreased slightly $(-22 \%)$. Assuming the metabolite alterations to primarily reflect changes in cellular composition, the observed pattern indicates early axonal involvement or loss as well as relatively enhanced turnover of myelin. These early stages are followed by a complete cellular loss in cerebral WM. (Pediatr Res 63: 444-449, 2008)
\end{abstract}

$\mathrm{V}$ anishing white matter (VWM) disease (MIM 603836) also known as myelinopathia centralis diffusa and childhood ataxia with diffuse central nervous system hypomyelination-was first separated from the vast group of unknown leukoencephalopathies in the early 90 s $(1,2)$. The MR imaging (MRI) and MR spectroscopy (MRS) features of VWM are unique and therefore considered diagnostic. MRI characteristically reveals bilaterally symmetric, diffuse involvement of cerebral white matter (WM) at the onset of symptoms and progressive cystic degeneration into an appearance like cerebrospinal fluid (CSF) over the course of the disease (3). Proton MRS shows a reduction of all WM metabolites except for the presence of lactate (Lac) and glucose (Glc) in concentrations typical for CSF $(1,4,5)$.

Received August 6, 2007; accepted November 23, 2007

Correspondence: Steffi F. Dreha-Kulaczewski, M.D., Department of Pediatrics and Pediatric Neurology, Georg August University, Robert-Koch-Str. 40, 37075 Goettingen, Germany; e-mail: sdreha@gwdg.de

Supported by the German Bundesministerium für Bildung und Forschung 01GM0309 (KB) and by the German Volkswagen Stiftung (PD).

DOI: 10.1203/01.pdr.0000304934.90198.25
Several phenotypic variations have been described encompassing i) rapidly fatal variants with antenatal onset and involvement of multiple organs, ii) onset in early infancy before 2 years of age (6-10), iii) a classical form with onset in late infancy/early childhood followed by a relapsingremitting/chronic progression over half a decade $(1,2,11-15)$, iv) juvenile onset cases with a protracted progression over 1-2 decades (3), and v) mild adolescence/adult forms, in females often associated with ovarian failure (16-22).

The mode of inheritance is autosomal recessive. Mutations in each of the five subunits $\alpha-\epsilon$ of the eucaryotic translation initiation factor 2B (eIF2B) have been found to cause the disease in most patients (23). eIF2B plays an essential role for initiation and regulation of cell protein synthesis. There is growing evidence that the mutations cause a decrease in eIF2B activity by different mechanisms and to a different extent. They may impair the ability of the subunits to form holocomplexes, and diminish the nucleotide exchange activity, or reduce the ability of the catalytic domain of the $\epsilon$ subunit to bind to the substrate, or actually enhance the binding (24). Another group reported a compromised generation of astrocytes positive for glial fibrillary acidic protein, thus raising the possibility of a functional deficiency $(25,26)$. Certainly, the pathogenesis of VWM is still not fully understood (27). Early histopathological work discussed hypomyelination versus demyelination $(1,3,28)$, while the observation of a commensurate degeneration of axons and myelin sheaths in cerebral WM prompted the hypothesis of a primary axonopathy (3). More recent studies, however, point toward a primary glial dysfunction which predominantly affects astrocytes and the myelin-producing oligodendrocytes $(27,29,30)$. Phosphorous MRS of patients with childhood ataxia with diffuse central nervous system hypomyelination revealed abnormal cerebral concentrations of high-energy phosphates

\footnotetext{
Abbreviations: Cho, choline-containing compounds; CSF, cerebrospinal fluid; eIF2B, eucaryotic translation initiation factor 2 B; Glc, glucose; GM, grey matter; Ins, myo-inositol; Lac, lactate; MRS, magnetic resonance spectroscopy; tCr, creatine and phosphocreatine; tNAA, $N$-acetyl-aspartate and $\mathrm{N}$-acetyl-aspartyl-glutamate; VOI, volume of interest; WM, white matter; VWM, vanishing white matter
} 
suggesting an impairment of myelin membrane synthesis or transport (31).

Histologically, the disease is characterized by cystic cavitations of the deep cerebral WM due to diffuse loss of both myelin and axons accompanied by a variable but generally meager astrogliosis and macrophage response (32). Regions of relatively preserved WM tissue may be adjacent to the cavitations. Although these regions often exhibit a paradoxically increased oligodendrocytic density, abundant cytoplasm, and vacuolation gives many of them a foamy appearance. Also dysmorphic astrocytes have been observed (29,30). Axonal involvement has been reported to vary highly from a complete loss in cavitations to a more variable loss in less involved areas to being relatively spared in other areas and cases (32).

The purpose of this study was to elucidate the extent of axonal involvement at early stages in infantile and early childhood forms of VWM and monitor the time course of progression as observable by single-voxel proton MRS with absolute quantification of metabolite concentrations.

\section{PATIENTS AND METHODS}

Patients. We investigated nine patients (five females) with a genetically proven diagnosis of VWM. The age at entering the study ranged between 20 mo and $26 \mathrm{y}$ (mean $8 \pm 6.3 \mathrm{y}$ ). Table 1 summarizes the clinical features of all the patients. The age at disease onset ranged between 1.6 and 4.5 y (mean $2.9 \pm$ $0.9 \mathrm{y})$. In eight patients, the onset of symptoms was provoked by a minor trauma $(n=3)$ or a febrile infection $(n=5)$. In patient 6 , no provoking event could be ascertained. Genetic analysis as described by Ohlenbusch et al. (33) yielded mutations in one of the five subunits of eIF2B in all nine patients. The histopathological findings of patient 1 have been published previously (34).

MRI/MRS. All the patients underwent combined MRI and localized proton MRS of cerebral WM and cortical gray matter (GM). Multiple follow-up studies were performed in three patients covering a period of 6 mo to $8 \mathrm{y}$. In five of the nine patients, the first measurement was obtained within 2 years after the onset of symptoms, ranging between 1 and 17 mo (mean $8 \pm$ $6.2 \mathrm{mo}$ ). The studies were approved by the local Ethics committee. Before each examination informed written consent was obtained from the parents. If necessary, children were sedated and monitored by pulse oximetry.

A total of 20 MRS investigations were carried out at $2 \mathrm{~T}$ (Magnetom SP and Vision, Siemens, Erlangen, Germany) using the standard imaging head coil. Fully relaxed short-echo time proton MR spectra were acquired using a single-voxel stimulated echo acquisition mode sequence (64 accumulations, repetition time $=6000 \mathrm{~ms}$, echo time $=20 \mathrm{~ms}$, middle interval $=30 \mathrm{~ms}$ for $\mathrm{SP}$ and $10 \mathrm{~ms}$ for Vision) as described previously $(35,36)$. Volumes of interest
(VOI) were chosen from T1-weighted three-dimensional fast low-angle shot images and T2-weighted (fast spin echo) images with sizes ranging from 3.9 to $18 \mathrm{~mL}$ in WM and 4.9 to $18 \mathrm{~mL}$ in GM. VOI locations included frontal and parieto-occipital WM and paramedian parietal GM (Fig. 1D).

Spectral evaluation and quantification of absolute metabolite concentrations were accomplished by fitting a linear combination of calibrated spectra of individual compounds using LCModel (37). Metabolite concentrations are expressed in mmol per liter VOI without corrections for CSF contributions and residual relaxation effects. A two-sided $t$ test was performed and $p$ values $<0.01$ were regarded as significantly different from a group of age-matched controls $(38,39)$

\section{RESULTS}

MRI. In all the patients, MRI revealed bilaterally symmetric and diffuse homogeneous signal alterations in hemispheric WM leading to hyperintensities on fluid-attenuated inversionrecovery (FLAIR) images (Fig. $1 A-C$ ) and T2-weighted images (Fig. $1 D-E)$ at early stages of the disease. The vanishing of the WM and its replacement by CSF-like fluid could be best appreciated on FLAIR images, as shown in Fig. $1 A-C$ for patient 9, where the initial high intensity of the WM signal gradually decreased during disease progression. At the final stage, only a faint ventricular lining and a meshwork of tissue strands extending between the ventricular lining and the cortex remained discernable. In the course of the disease, other structures such as the internal capsule and subcortical U-fibers became involved in the degenerative process. In all the patients, the central tegmental tract showed pathologic signal intensity. MRI of the two oldest patients 4 and 5 revealed T2-weighted signal attenuation in the putamen. In all the patients, except for patients 3 and 7, the cerebellar WM displayed a progressive T2-weighted signal increase indicating disease involvement. After the application of a contrast agent (patients 2, 3, and 9), no enhancement could be detected.

MRS. Figure $2 A$ shows a WM spectrum of patient 2 (early childhood form) obtained 11 mo after the onset of disease. It reveals a significant reduction of $\mathrm{N}$-acetyl-aspartate and $\mathrm{N}$ acteyl-aspartyl-glutamate (tNAA), creatine and phosphocreatine ( $\mathrm{tCr}$ ), and myo-inositol (Ins) compared with the spectrum of an age-matched normal control (Fig. 2B). Cholinecontaining compounds (Cho) are less severely affected and

Table 1. Summary of clinical, neurological, and genetic findings

\begin{tabular}{|c|c|c|c|c|c|c|c|c|c|}
\hline Patient & 1 & 2 & 3 & 4 & 5 & 6 & 7 & 8 & 9 \\
\hline Gender & Male & Male & Male & Female & Female & Female & Male & Female & Female \\
\hline Ability to walk (mo) & 16 with support & NA & 15 unstable & 14 & 9 & 15 unstable & NA & 12 & 13 clumsy \\
\hline $\begin{array}{l}\text { Initial mental } \\
\text { development }\end{array}$ & Normal & Normal & Delayed & Normal & Normal & Normal & Normal & Speech delay & Normal \\
\hline Symptoms onset (y) & 1.6 & 2.3 & 4 & 2.5 & 4.5 & 2.5 & 2.8 & 2.3 & 3.6 \\
\hline Provoking event: & & & & & & None & & & \\
\hline Trauma & & + & + & & & & & & + \\
\hline Infections & + & & & + & + & & + & + & \\
\hline Loss of walking (y) & 1.6 & 10.3 & None & 2.5 & 4.5 & 3.5 & 3.5 & 3.3 & 4.2 \\
\hline Age at MRS (y) & 1.8 & $\begin{array}{l}3.3,3.9,4.2,5.7 \\
\quad 6.2,6.9,8.1 \\
9.7,10.8\end{array}$ & 4.6 & 21.1 & 26.4 & $9.5,10.4,16.7$ & 3.4 & 6.8 & $4.1,4.6$ \\
\hline $\begin{array}{l}\text { Familial } \\
\text { occurrence }\end{array}$ & $\begin{array}{l}\text { 2nd cousins } \\
\text { affected (2) }\end{array}$ & No & No & Yes (patient 5) & Yes (patient 4) & No & NA & No & No \\
\hline Mutation: & EIF2B5/ & EIF2B3/ & $E I F 2 B 2 /$ & $E I F 2 B 2 /$ & $E I F 2 B 2 /$ & EIF2B4/ & EIF 2B3/ & EIF2B5/ & $E I F 2 B 3 /$ \\
\hline Gene/protein level & $\begin{array}{l}\text { p.Arg269Gly } \\
\text { p.Arg269Gly }\end{array}$ & $\begin{array}{l}\text { p.Val30Gly } \\
\text { p.Ala87Val }\end{array}$ & $\begin{array}{l}\text { Pro196Ser } \\
\quad \text { Glu213Gly }\end{array}$ & Glu213Gly & Glu213Gly & $\begin{array}{l}\text { p.Leu269Arg } \\
\text { p.Arg374Cys }\end{array}$ & Arg225Gln & $\begin{array}{l}\text { p.Ala74Thr/ } \\
\text { p.Cys335Arg }\end{array}$ & Arg226Gln \\
\hline $\begin{array}{l}\text { Present age (age } \\
\text { at death) (y) }\end{array}$ & (1.8) & 15.5 & 10.6 & 25.4 & 30.6 & 21.4 & 14 & NA & 8.8 \\
\hline
\end{tabular}

NA indicates not available. 


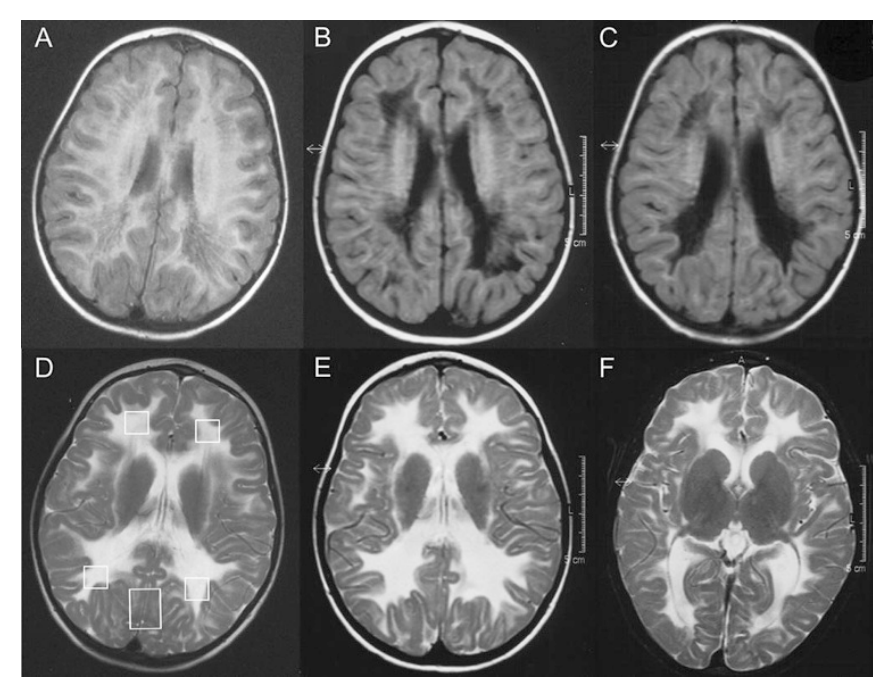

Figure 1. Representative FLAIR $(A-C)$ and T2-weighted $(D-F)$ images of patient 9 at $(A, D)$ onset of symptoms as well as $(B, E) 10$ mo and $(C, F) 4.6 \mathrm{y}$ later. In FLAIR images, the hemispheric WM has abnormally high signal intensity at disease onset, whereas bilateral parieto-occipital areas already presented as hypointense. WM intensities further decrease with progressive cystic degeneration. In T2-weighted images, WM presented as hyperintense throughout the entire time of study. Image $(D)$ depicts typical VOI locations chosen for MRS.
A

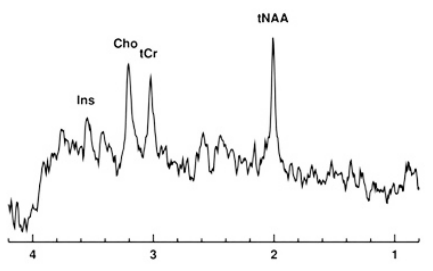

C

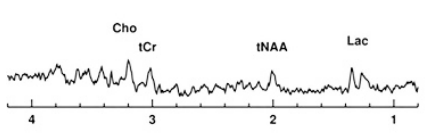

$E$

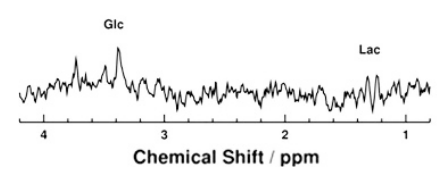

B

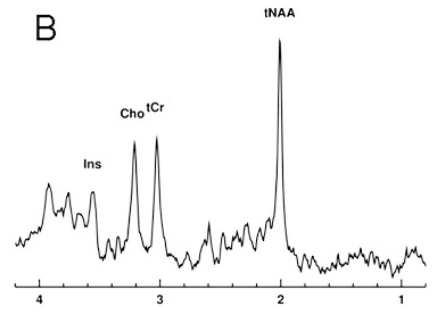

D

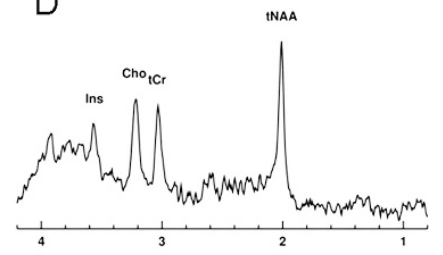

$\mathrm{F}$

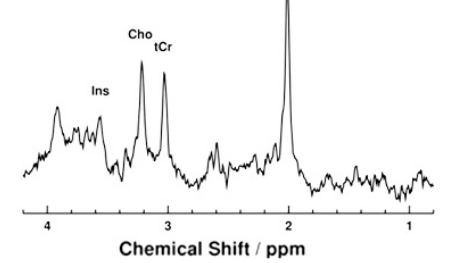

Figure 2. Proton MR spectra of WM of patient 2 obtained at $(A) 11$ mo (age $3.3 \mathrm{y}$ ), (C) $4.5 \mathrm{y}$ (age $6.9 \mathrm{y}$ ), and $(E) 8.6 \mathrm{y}$ (age $10.8 \mathrm{y}$ ) after the onset of symptoms in comparison to age-matched controls $(B, D$, and $F)$. The reduction of metabolite signals in early phases of the disease is followed by a further decrease during disease progression. In advanced stages, only Glc and Lac remain discernable closely resembling the pattern found for CSF.

show a milder signal decrease. Figures $2 C$ and $E$ demonstrate the alterations over time with progressive decrease of all metabolites until they are indistinguishable from the noise level. This process is accompanied by the simultaneous rise of
Lac and Glc. Figures $2 D$ and $F$ show proton MR spectra of WM of age-matched controls.

Table 2 summarizes the absolute concentrations of tNAA, $\mathrm{tCr}$, Cho, Ins, Glc, and Lac of all the patients over the period of observation. In the first MRS obtained within 24 mo after onset of symptoms tNAA $\left(p=10^{-6}\right), \operatorname{tCr}\left(p=0.9 \times 10^{-4}\right)$, and Ins $\left(p=0.9 \times 10^{-6}\right)$ were significantly reduced, whereas Cho $(p>0.05)$ showed only a tendency for reduced levels in comparison with controls. Over the later course, the concentrations of all metabolites decreased further $(\mathrm{tNAA} p=0.2 \times$ $10^{-7}$; tCr $p=0.6 \times 10^{-6}$; Cho $p=0.5 \times 10^{-6}$; Ins $p=$ $0.1 \times 10^{-9}$ ). Six patients (patients 1,2, 6, 7, 8, and 9) presented with increased Glc concentrations in at least one of the studies covering a period from 1 mo to $14.1 \mathrm{y}$ after symptom onset. Elevated Lac could be observed in all the patients except patient 3 at various time points of the disease between 1 mo (patient 1) and 22 y (patient 4) after onset of symptoms.

Figure 3 depicts the individual time courses of all WM metabolites for all the patients. Despite the heterogeneity of the clinical courses, all tNAA concentrations throughout the observation periods as well as most $\mathrm{tCr}$ and Ins concentrations were below the normal range here defined as 2 standard deviations (SD) below (or above) the respective mean concentrations of controls (horizontal lines in Fig. 3). Patient 2 followed a relapsing-remitting course where the clinical remission was paralleled by a temporary increase of tNAA and $\mathrm{tCr}$, while Cho and Ins continued to decrease. Patient 6 showed a fast progression of symptoms over 2 years yielding undetectable major metabolites. Patient 5 had a slow continuous progression over almost 2 decades that led to significantly lowered metabolite concentrations, except for Ins. Lac and Glc of patients 2, 5, and 6 did not vary according to the clinical pattern.

In patients with the early childhood form (patients 2 and 4-9) MRS of GM was essentially normal as shown for patient 2 in Fig. $4 A$ and $B$ obtained 11 mo and 8.6 y after the onset of symptoms (GM spectra of patient 3 were not available due to technical reasons). A group comparison of GM metabolite concentrations measured over time (Table 3 ) demonstrated only a slight decrease of tNAA $\left(p=0.5 \times 10^{-3}\right)$ concentration compared with controls. Elevated Lac was found in only 3 of $20 \mathrm{GM}$ spectra obtained in later stages of the disease at 4 and $7 \mathrm{y}$ after onset of symptoms (patient 2: $1.7 \mathrm{mM}$, patient 6: $3.3 \mathrm{mM}$, patient 8: $2.7 \mathrm{mM}$ ). Glc was increased in only one case (patient 2: $1.9 \mathrm{mM}$ ) 1.6 y after onset of symptoms.

Patient 1 with the late infantile form of VWM was the only one with GM alterations qualitatively similar to but less pronounced than those in WM. Concentrations of tNAA (3.3 $\mathrm{mM},-6 \mathrm{SD}$ from controls), $\mathrm{tCr}(4.3 \mathrm{mM},-3.8 \mathrm{SD})$, Ins (2.7 $\mathrm{mM},-2.7 \mathrm{SD})$, and Cho $(0.8 \mathrm{mM},-1.9 \mathrm{SD})$ were significantly reduced $1 \mathrm{mo}$ after the acute onset of symptoms. Lac was slightly elevated (up to $1.3 \mathrm{mM}$ ) and Glc was not detectable. The patient did not regain consciousness and died only 1 mo later.

\section{DISCUSSION}

The present MRS findings for nine VWM patients with an infantile and early childhood variant are in line with literature reports pointing to a generalized vanishing of WM. In agreement with the characteristic MRI features of VWM, the 
Table 2. Absolute metabolite concentrations in cerebral white matter of all VWM patients

\begin{tabular}{lcrc}
\hline & $\begin{array}{c}\text { Patients } 1-3,7,9 ; \text { first MRS }<2 \text { y } \\
\text { after onset of symptoms }(n=5)\end{array}$ & $\begin{array}{c}\text { Patients 2, 4-6, 8; all MRS }>2 \text { y } \\
\text { after onset of symptoms }(n=5)\end{array}$ & $6.9 \pm 0.6(n=17)$ \\
tNAA & $3.3^{*} \pm 1.1$ & $1.5^{*} \pm 1.5$ & $4.9 \pm 0.4(n=17)$ \\
tCr & $2.6^{*} \pm 1.3$ & $1.3^{*} \pm 1.3$ & $1.6 \pm 0.3(n=17)$ \\
Cho & $1.1 \pm 0.5$ & $0.4^{*} \pm 0.4$ & $3.7 \pm 0.6(n=17)$ \\
Ins & $1.9^{*} \pm 0.6$ & $0.3^{*} \pm 0.6$ & $0.7-1.2(n=11)$ \\
Glc & $4.2 \pm 1.1$ & $4.2 \pm 0.7$ & $0.4-0.6(n=11)$ \\
Lac & $2.1 \pm 0.1$ & $2.2 \pm 0.7$ & $17)$ \\
\hline
\end{tabular}

$* p<0.01$ (two sided $t$ test); concentrations are given in $\mathrm{mmol} / \mathrm{L}$ VOI and represent mean values $( \pm \mathrm{SD})$ averaged across subjects and respective observation periods; control values were obtained from age-matched subjects (age range 5-10 y) (38) except for Glc and Lac (39).
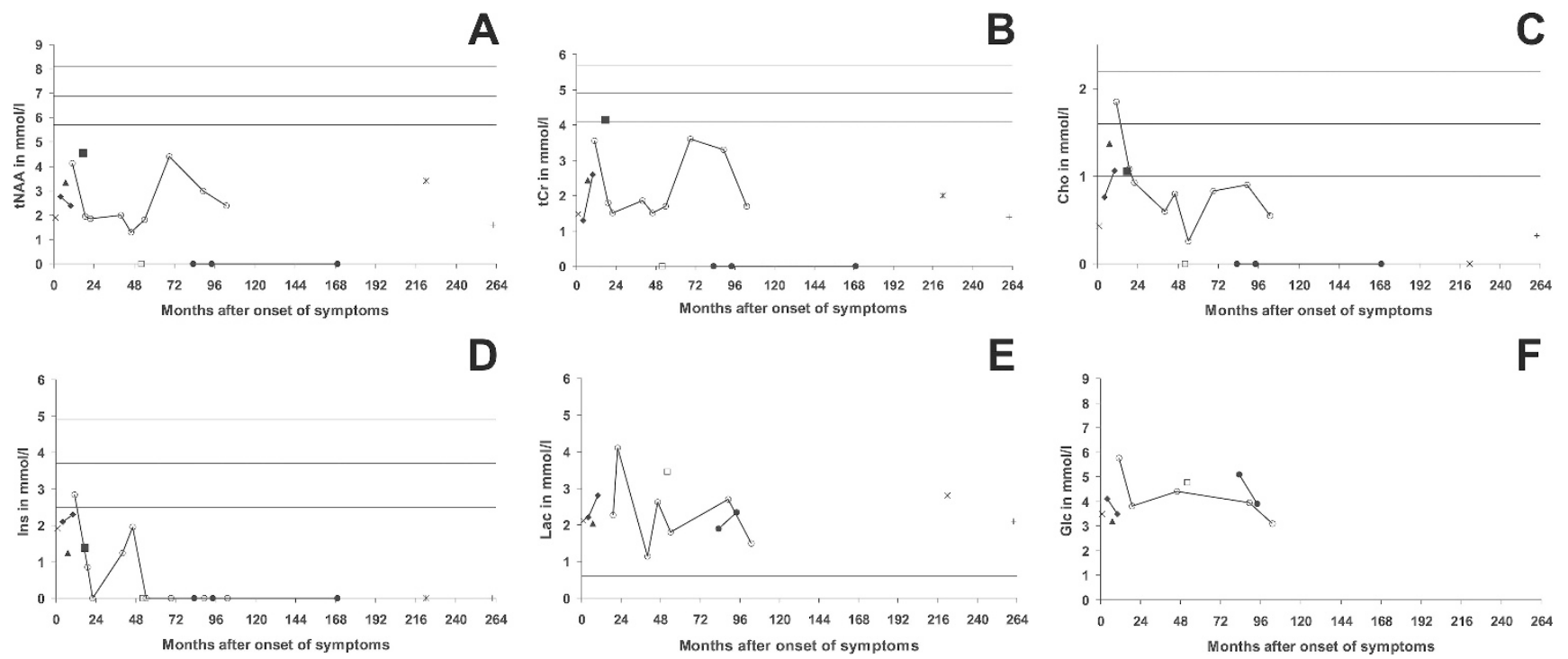

Figure 3. Absolute metabolite concentrations of $(A)$ tNAA, $(B) \mathrm{tCr},(C)$ Cho, $(D)$ Ins, $(E)$ Lac, and $(F)$ Glc in WM of patient $1(\times), 2(\bigcirc), 3(\square), 4(*), 5(+)$, $6(\bullet), 7(\Delta), 8(\square)$, and $9(\checkmark)$ over the whole observation period (connected data points refer to individual follow-up studies). tNAA is already reduced at early disease stages. Horizontal lines indicate mean values \pm 2 SD of age-matched controls.

cerebral metabolite levels were most markedly altered in WM. When followed up to over 8 years of the disease course, proton MRS revealed a depletion of all major metabolites at later stages reaching a CSF-like appearance. The finding of elevated concentrations of Glc and Lac in all the patients at all disease stages indicates enhanced nonoxidative glucose consumption. This observation might reflect the anaerobic metabolism of macrophages involved in the clearance of cellular debris from ongoing neurodegeneration. Conversely, and except for the patient with late infantile onset, the metabolite levels in GM remained remarkably unaltered throughout the observation period.

Significant WM alterations already occurred at an early stage of the disease within the first 2 years after the onset of symptoms. This period is characterized by a significant reduction of tNAA, tCr, and Ins, and a milder decrease of Cho. Assuming these findings to primarily reflect changes in cellular composition rather than intracellular metabolism, the observed tNAA reduction refers to a significant loss of viable axons already at early disease stages in infantile and early childhood form of VWM. This is supported by the fact that previous studies not only demonstrated tNAA to be predominantly localized within neurons and axons but also validated tNAA as an axon-specific marker of cerebral WM (40-42). At later disease stages, a loss of vital neuro-axonal tissue in cavitated deep cerebral WM areas is unquestionable. How-

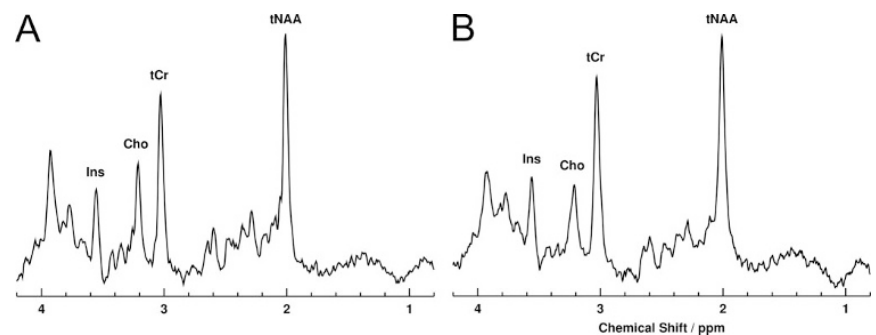

Figure 4. Proton MR spectra of GM of patient 2 obtained at $(A) 11$ mo and (B) 8.6 y after the onset of symptoms in early childhood. Except for a slight decrease of tNAA, both spectra reveal essentially normal metabolite signals.

Table 3. Absolute metabolite concentrations in cerebral grey matter of VWM patients with the early childhood form

\begin{tabular}{lcc}
\hline & Patients $2,4-9(n=7)$ & Controls $(n=17)$ \\
\hline tNAA & $6.4^{*} \pm 1.2$ & $8.2 \pm 0.8$ \\
tCr & $5.7 \pm 1.1$ & $6.2 \pm 0.5$ \\
Cho & $1.1 \pm 0.2$ & $1.2 \pm 0.2$ \\
Ins & $3.8 \pm 0.7$ & $4.6 \pm 0.7$ \\
\hline
\end{tabular}

$* p<0.01$ (two sided $t$ test); concentrations are given in mmol/L VOI and represent mean values $( \pm \mathrm{SD})$ averaged across patients and the observation period; control values were obtained from age-matched subjects (age range 5-10 y) (38). For Glc and Lac see Results section.

ever, in less affected WM and/or at intermediate disease stages the axonal involvement is known to be variable up to relative preservation $(2,43)$. The assumption that axonal loss solely 
emerges as a secondary process-similar to other classic leukodystrophies - should yield a slower decline of tNAA than observed here, where tNAA concentrations were markedly reduced as early as 4-7 mo after the onset of symptoms. Of course, because all MRS studies were performed after the onset of symptoms, one cannot speculate about presymptomatic metabolite alterations and the causal nature of the present observations. At least one patient has been reported to exhibit only mildly reduced NAA levels soon after the onset of symptoms (4). However, as we cannot compare the severity of clinical courses, such findings might be attributed to individual variations in axonal involvement (32).

The Ins signal detected by MRS arises from free myoinositol, which is considered the most important nonnitrogenous organic osmolyte in brain tissue and has been found in high concentrations in astrocytes (44). Similar to tNAA, its low concentration may be interpreted as a loss of respective cells in agreement with the disproportional feeble astrogliosis in VWM (27). Together, the lowered number/density of axons and astrocytes is perfectly in line with the proportional decrease of $\mathrm{tCr}$ as creatine and phosphocreatine are constituents of both neuronal and glial cells (45).

The reduction of the Cho concentration was less pronounced. The MRS-detectable Cho resonance comprises phosphorylcholine and phosphoryl-ethanolamine as precursor molecules for membrane synthesis as well as glycerophosphorylcholine and glycerophosphorylethanolamine as the corresponding membrane degradation products. Elevated Cho concentrations may thus either arise from enhanced membrane turnover [e.g., in young infants (38)] and cell proliferation [e.g., in brain tumors (46)] or from accumulation of myelin breakdown products as typically seen during demyelination (47). On the other hand, and apart from an end-stage scenario, a diminished Cho level has only been described in cases of hypomyelination such as Pelizaeus-Merzbacher disease (48).

Despite the increased oligodendrocyte cell count in betterpreserved WM regions, the amount of stainable myelin has been found to be decreased in VWM disease. Up to this point it remains unclear if the myelin deficit reflects true hypomyelination and whether this is due to oligodendrocytic immaturity or mere dysfunction (29). However, regardless of the precise origin, insufficient myelination in the presence of some degree of deymelination as well as enhanced turnover of myelin may explain the low but-in comparison with tNAA and Ins levels-relatively high Cho concentration.

In patients with the early childhood form, the absence of essential metabolite alterations in GM is in line with its striking preservation on MRI. Over time, only a slight decrease of tNAA was observable which may indicate a subtle neuronal atrophy. In contrast, the one patient who presented with a disease onset in early infancy and a severe subacute clinical progression showed similar though less pronounced GM alterations than in WM. In view of the rapidly fatal course of this patient, these results might be attributed to an acute encephalopathy with severe metabolic perturbation.

A comparison of WM and GM metabolites supports the assumption of VWM being a disease of glial cells. Oligodendrocytes seem to be particularly vulnerable to reduced eIF2B activity which is assumed to impair the cellular response to conditions of stress-like fever $(32,49)$. This in turn might contribute to activation of cell-death signaling pathways.

In conclusion, this follow-up quantitative proton MRS study adds valuable information about the time course of the axonal and glial involvement in infantile and early childhood variants of VWM. During early stages of up to 2 years after the first onset of symptoms, the cerebral metabolite pattern is characterized by a pronounced reduction of tNAA. Ins and $\mathrm{tCr}$ are similarly reduced but to a more variable extent, whereas Cho is only slightly decreased. These observations may be understood as a partial loss of both glial cells and axons already at early disease stages. The reduced but relatively high level of Cho would be in line with insufficiently myelinated axons possibly in the presence of ongoing demyelinating processes.

Although there is mounting evidence for a primary myelin defect in VWM, the early and invariable tNAA decrease points to a severe axonal involvement already at disease onset_-possibly one of the factors responsible for the clinical symptoms. On the other hand, due to the lack of data from presymptomatic stages, conclusions about the initial (and perhaps causative) events cannot be drawn by in vivo MRS.

\section{REFERENCES}

1. Hanefeld F, Holzbach U, Kruse B, Wilichowski E, Christen HJ, Frahm J 1993 Diffuse white matter disease in three children: an encephalopathy with unique features on magnetic resonance imaging and proton magnetic resonance spectroscopy. Neuropediatrics 24:244-248

2. Schiffmann R, Moller JR, Trapp BD, Shih HH, Farrer RG, Katz DA, Alger JR, Parker CC, Hauer PE, Kaneski CR, Heiss JD, Kaye EM, Quarles RH, Brady RO, Barton NW 1994 Childhood ataxia with diffuse central nervous system hypomyelination. Ann Neurol 35:331-340

3. van der Knaap MS, Kamphorst W, Barth PG, Kraaijeveld CL, Gut E, Valk J 1998 Phenotypic variation in leukoencephalopathy with vanishing white matter. Neurology 51:540-547

4. van der Knaap MS, Barth PG, Gabreels FJ, Franzoni E, Begeer JH, Stroink H, Rotteveel JJ, Valk J 1997 A new leukoencephalopathy with vanishing white matter. Neurology 48:845-855

5. Tedeschi G, Schiffmann R, Barton NW, Shih HH, Gospe SM Jr, Brady RO, Alger JR, Di Chiro G 1995 Proton magnetic resonance spectroscopic imaging in childhood ataxia with diffuse central nervous system hypomyelination. Neurology 45:15261532

6. van der Knaap MS, van Berkel CG, Herms J, van Coster R, Baethmann M, Naidu S, Boltshauser E, Willemsen MA, Plecko B, Hoffmann GF, Proud CG, Scheper GC, Pronk JC 2003 eIF2B-related disorders: antenatal onset and involvement of multiple organs. Am J Hum Genet 73:1199-1207

7. Francalanci P, Eymard-Pierre E, Dionisi-Vici C, Boldrini R, Piemonte F, Virgili R, Fariello G, Bosman C, Santorelli FM, Boespflug-Tanguy O, Bertini E 2001 Fatal infantile leukodystrophy: a severe variant of $\mathrm{CACH} / \mathrm{VWM}$ syndrome, allelic to chromosome 3q27. Neurology 57:265-270

8. Fogli A, Wong K, Eymard-Pierre E, Wenger J, Bouffard JP, Goldin E, Black DN, Boespflug-Tanguy O, Schiffmann R 2002 Cree leukoencephalopathy and CACH/ VWM disease are allelic at the EIF2B5 locus. Ann Neurol 52:506-510

9. Boltshauser E, Barth PG, Troost D, Martin E, Stallmach T 2002 "Vanishing white matter" and ovarian dysgenesis in an infant with cerebro-oculo-facio-skeletal phenotype. Neuropediatrics 33:57-62

10. Fogli A, Dionisi-Vici C, Deodato F, Bartuli A, Boespflug-Tanguy O, Bertini E 2002 A severe variant of childhood ataxia with central hypomyelination/vanishing white matter leukoencephalopathy related to EIF21B5 mutation. Neurology 59:1966-1968

11. Sugiura C, Miyata H, Oka A, Takashima S, Ohama E, Takeshita K 2001 A Japanese girl with leukoencephalopathy with vanishing white matter. Brain Dev 23:58-61

12. Topcu M, Saatci I, Apak RA, Soylemezoglu F 2000 A case of leukoencephalopathy with vanishing white matter. Neuropediatrics 31:100-103

13. Wilson CJ, Pronk JC, Van der Knaap MS 2005 Vanishing white matter disease in a child presenting with ataxia. J Paediatr Child Health 41:65-67

14. Rosemberg S, Leite Cda C, Arita FN, Kliemann SE, Lacerda MT 2002 Leukoencephalopathy with vanishing white matter: report of four cases from three unrelated Brazilian families. Brain Dev 24:250-256

15. Vermeulen G, Seidl R, Mercimek-Mahmutoglu S, Rotteveel JJ, Scheper GC, van der Knaap MS 2005 Fright is a provoking factor in vanishing white matter disease. Ann Neurol 57:560-563

16. Fogli A, Rodriguez D, Eymard-Pierre E, Bouhour F, Labauge P, Meaney BF, Zeesman S, Kaneski CR, Schiffmann R, Boespflug-Tanguy O 2003 Ovarian failure related to eukaryotic initiation factor $2 \mathrm{~B}$ mutations. Am J Hum Genet 72:1544-1550 
17. Gallo A, Rocca MA, Falini A, Scaglione C, Salvi F, Gambini A, Guerrini L, Mascalchi M, Pronk JC, van der Knaap MS, Filippi M 2004 Multiparametric MRI in a patient with adult-onset leukoencephalopathy with vanishing white matter. Neurology 62:323-326

18. van der Knaap MS, Leegwater PA, van Berkel CG, Brenner C, Storey E, Di Rocco M, Salvi F, Pronk JC 2004 Arg113His mutation in eIF2Bepsilon as cause of leukoencephalopathy in adults. Neurology 62:1598-1600

19. Biancheri R, Rossi A, Di Rocco M, Filocamo M, Pronk JC, van der Knaap MS Tortori-Donati P 2003 Leukoencephalopathy with vanishing white matter: an adult onset case. Neurology 61:1818-1819

20. Prass K, Brück W, Schroder NW, Bender A, Prass M, Wolf T, Van der Knaap MS, Zschenderlein R 2001 Adult-onset Leukoencephalopathy with vanishing white matter presenting with dementia. Ann Neurol 50:665-668

21. Ohtake H, Shimohata T, Terajima K, Kimura T, Jo R, Kaseda R, Iizuka O, Takano M, Akaiwa Y, Goto H, Kobayashi H, Sugai T, Muratake T, Hosoki T, Shioiri T, Okamoto K, Onodera O, Tanaka K, Someya T, Nakada T, Tsuji S 2004 Adult-onse leukoencephalopathy with vanishing white matter with a missense mutation in EIF2B5. Neurology 62:1601-1603

22. Denier C, Orgibet A, Roffi F, Jouvent E, Buhl C, Niel F, Boespflug-Tanguy O, Said G, Ducreux D 2007 Adult-onset vanishing white matter leukoencephalopathy presenting as psychosis. Neurology 68:1538-1539

23. van der Knaap MS, Leegwater PA, Konst AA, Visser A, Naidu S, Oudejans CB, Schutgens RB, Pronk JC 2002 Mutations in each of the five subunits of translation initiation factor eIF2B can cause leukoencephalopathy with vanishing white matter. Ann Neurol 51:264-270

24. Li W, Wang X, Van Der Knaap MS, Proud CG 2004 Mutations linked to leukoencephalopathy with vanishing white matter impair the function of the eukaryotic initiation factor 2B complex in diverse ways. Mol Cell Biol 24:3295-3306

25. Dietrich J, Lacagnina M, Gass D, Richfield E, Mayer-Proschel M, Noble M, Torres C, Proschel C 2005 EIF2B5 mutations compromise GFAP+ astrocyte generation in vanishing white matter leukodystrophy. Nat Med 11:277-283

26. Fogli A, Boespflug-Tanguy O 2006 The large spectrum of eIF2B-related diseases. Biochem Soc Trans 34:22-29

27. Scheper GC, Proud CG, van der Knaap MS 2006 Defective translation initiation causes vanishing of cerebral white matter. Trends Mol Med 12:159-166

28. Rodriguez D, Gelot A, della Gaspera B, Robain O, Ponsot G, Sarlieve LL, Ghandour S, Pompidou A, Dautigny A, Aubourg P, Pham-Dinh D 1999 Increased density of oligodendrocytes in childhood ataxia with diffuse central hypomyelination $(\mathrm{CACH})$ syndrome: neuropathological and biochemical study of two cases. Acta Neuropatho (Berl) 97:469-480

29. Van Haren K, van der Voorn JP, Peterson DR, van der Knaap MS, Powers JM 2004 The life and death of oligodendrocytes in vanishing white matter disease. J Neuropathol Exp Neurol 63:618-630

30. van der Voorn JP, van Kollenburg B, Bertrand G, Van Haren K, Scheper GC, Powers JM, van der Knaap MS 2005 The unfolded protein response in vanishing white matter disease. J Neuropathol Exp Neurol 64:770-775

31. Bluml S, Philippart M, Schiffmann R, Seymour K, Ross BD 2003 Membrane phospholipids and high-energy metabolites in childhood ataxia with CNS hypomyelination. Neurology 61:648-654
32. van der Knaap MS, Pronk JC, Scheper GC 2006 Vanishing white matter disease Lancet Neurol 5:413-423

33. Ohlenbusch A, Henneke M, Brockmann K, Goerg M, Hanefeld F, Kohlschutter A, Gartner J 2005 Identification of ten novel mutations in patients with eIF2B-related disorders. Hum Mutat 25:411

34. Brück W, Herms J, Brockmann K, Schulz-Schaeffer W, Hanefeld F 2001 Myelinopathia centralis diffusa (vanishing white matter disease): evidence of apoptotic oligodendrocyte degeneration in early lesion development. Ann Neurol 50:532-536

35. Frahm J, Michaelis T, Merboldt KD, Bruhn H, Gyncell ML, Hänicke W 1990 Improvements in localized proton NMR spectroscopy of human brain. Water suppression, short echo times, and $1 \mathrm{ml}$ resolution. J Magn Reson 90:464-473

36. Frahm J, Hanefeld F 1996 Localized proton magnetic resonance spectroscopy of cerebral metabolites. Neuropediatrics 27:64-69

37. Provencher SW 1993 Estimation of metabolite concentrations from localized in vivo proton NMR spectra. Magn Reson Med 30:672-679

38. Pouwels PJ, Brockmann K, Kruse B, Wilken B, Wick M, Hanefeld F, Frahm J 1999 Regional age dependence of human brain metabolites from infancy to adulthood as detected by quantitative localized proton MRS. Pediatr Res 46:474-485

39. Frahm J, Krüger G, Merboldt KD, Kleinschmidt A 1996 Dynamic uncoupling and recoupling of perfusion and oxidative metabolism during focal brain activation in man. Magn Reson Med 35:143-148

40. Moffett JR, Namboodiri MA, Cangro CB, Neale JH 1991 Immunohistochemical localization of $N$-acetylaspartate in rat brain. Neuroreport 2:131-134

41. Simmons ML, Frondoza CG, Coyle JT 1991 Immunocytochemical localization of $\mathrm{N}$-acetyl-aspartate with monoclonal antibodies. Neuroscience 45:37-45

42. Bjartmar C, Battistuta J, Terada N, Dupree E, Trapp BD $2002 \mathrm{~N}$-acetylaspartate is an axon-specific marker of mature white matter in vivo: a biochemical and immunohistochemical study on the rat optic nerve. Ann Neurol 51:51-58

43. Wong K, Armstrong RC, Gyure KA, Morrison AL, Rodriguez D, Matalon R, Johnson AB, Wollmann R, Gilbert E, Le TQ, Bradley CA, Crutchfield K, Schiffmann R 2000 Foamy cells with oligodendroglial phenotype in childhood ataxia with diffuse central nervous system hypomyelination syndrome. Acta Neuropathol (Berl) 100:635-646

44. Brand A, Richter-Landsberg C, Leibfritz D 1993 Multinuclear NMR studies on the energy metabolism of glial and neuronal cells. Dev Neurosci 15:289-298

45. Urenjak J, Williams SR, Gadian DG, Noble M 1993 Proton nuclear magnetic resonance spectroscopy unambiguously identifies different neural cell types. J Neurosci 13:981-989

46. Wilken B, Dechent P, Herms J, Maxton C, Markakis E, Hanefeld F, Frahm J 2000 Quantitative proton magnetic resonance spectroscopy of focal brain lesions. Pediat Neurol 23:22-31

47. Pouwels PJ, Kruse B, Korenke GC, Mao X, Hanefeld FA, Frahm J 1998 Quantitative proton magnetic resonance spectroscopy of childhood adrenoleukodystrophy. Neuropediatrics 29:254-264

48. Hanefeld FA, Brockmann K, Pouwels PJ, Wilken B, Frahm J, Dechent P 2005 Quantitative proton MRS of Pelizaeus-Merzbacher disease: evidence of dys- and hypomyelination. Neurology 65:701-706

49. Schiffmann R, Elroy-Stein O 2006 Childhood ataxia with CNS hypomyelination vanishing white matter disease-a common leukodystrophy caused by abnormal control of protein synthesis. Mol Genet Metab 88:7-15 